The vision of the Office of Motor Carriers is to help move people, goods, and commercial motor vehicles on our Nation's highways in the most efficient, economical, and crash-free manner possible. The OMC research and technology program focuses on improving safety in interstate commercial motor vehicle operations and serves a trucking and motor coach industry that carries more than $\mathbf{4 0}$ percent of all intercity freight.

Studies are conducted in the following areas: commercial driver human factors, health, and performance needs; new and emerging driver and vehicle technologies; safetyrelated data collection and analysis needs; and performance-based changes to the Federal Motor Carrier Safety Regulations.

The OMC's human factors research projects aim to promote alert, healthy drivers and seek to improve the uniformity and effectiveness of driver training and licensing.

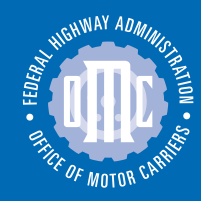

Office of Motor Carrier Research and Standards

400 Seventh Street, SW

HCS-30; Room 3107

Washington, DC 20590

\section{Commercial Driver Rest \& Parking Requirements: Making Space for Safety}

\section{Introduction}

The ability of commercial motor vehicle operators to safely stop and rest is a special concern to commercial motor vehicle transportation. This Tech Brief presents a Federal Highway Administration study that addressed the adequacy of both public and private parking facilities nationwide. More information about this study can be found in a separate report (FHWA-MC-96-0010) of the same title.

\section{Purpose}

The steady growth in trucking nationwide appears to have increased the demand for rest areas along the nation's highways. Commercial drivers need a safe place to park, especially at night, to maintain their alertness. A growing concern about commercial driver fatigue has created a need to assure public safety along the highways.

The primary goal of this study was to consider parking statutes and enforcement, and to determine the supply, utilization, and demand for truck parking at both rest areas (public facilities) and truck stops (privately-owned facilities). Researchers sought to address a perceived need for additional parking space through direct observation, interviews, statistical sampling and evaluations, modeling, and demographic data collection.

\section{Research Methodology}

Prior rest area research has typically concentrated on analyzing data at the individual Interstate corridor level. In order to undertake empirical research at the state and national level, this study generated the first nationwide inventory of public rest areas along Interstate highways, as well as projections of parking area availability and demand at public rest areas and privately-owned truck stops.

The initial phase of the research concentrated on the current status of public rest area parking for trucks. Researchers relied on three general methods of data collection:

- An inventory of parking capacity and restrictions at 1,487 public rest areas in the 48 contiguous states.

- Direct observation of the actual use of truck parking at facilities along a mediumdensity trucking corridor. Researchers collected information through peak-period surveillance of truck parking activities along a 200-mile segment of I-81 from Radford, Virginia to Knoxville, Tennessee.

- A series of interviews and surveys that consulted 500 truck drivers, 330 motor carriers, and 170 truck stop operators. 


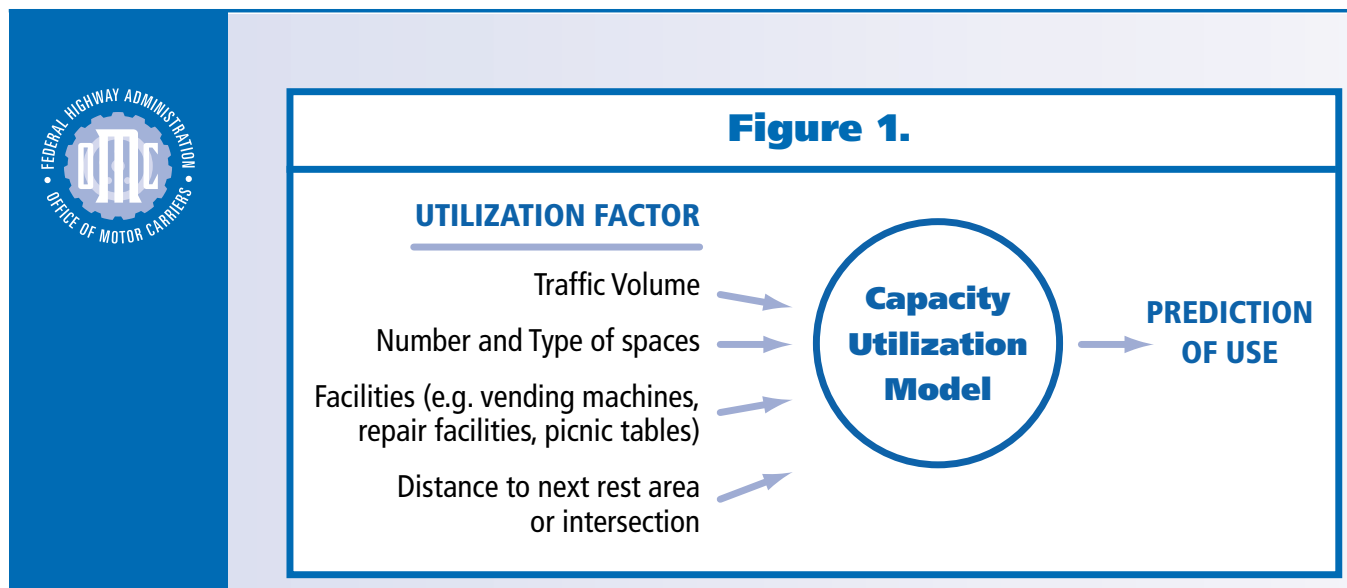

drivers and the need for additional truck parking spaces at rest areas along the Interstates.

The Capacity Utilization Model identified the services and facilities that affect the utilization of truck parking at public rest areas, as illustrated in Figure 1. Using data from 709 rest areas located across the country, this model estimated the individual impact of variables that affect the utilization of parking spaces, such

Table 1.

Types of Truck Parking Services Provided by Privately-Owned Truck Stops (Weighted Base)

\begin{tabular}{|l|l|}
\hline Free Truck Parking & $94 \%$ \\
\hline Lighted Parking & $92 \%$ \\
\hline Paved Parking & $86 \%$ \\
\hline Marked Parking Spaces & $55 \%$ \\
\hline Secured at Night & $18 \%$ \\
\hline Able to Accommodate & $73 \%$ \\
\hline Non-Standard Trucks & $71 \%$ \\
\hline Oversized Trucks & $51 \%$ \\
\hline Triples & $30 \%$ \\
\hline Hazmat Trucks & \\
\hline
\end{tabular}

Upon completion of the public rest area portion of the study, a second survey was conducted to assess the supply and demand for parking at privatelyowned truck stops. Researchers mailed survey questionnaires to 987 members of the National Association of Truck Stop Operators in order to obtain feedback from a representative sample of truck stop operators nationwide. Responses were received from 381 , or 39 percent, of them, providing information on truck parking capacity, usage, and space availability.

Drawing on other information about privately-owned truck stop distribution in the U.S., the contractor determined that those responding to the questionnaire were primarily large facilities ( 80 or more parking spaces) and tended to represent some areas of the nation more extensively than others. Therefore, researchers used statistical weighting procedures to adjust these deviations in both size and regional distribution to ensure that the final survey results could be accurately projected to the total target population.

\section{Models}

This research led to the development and testing of two models to analyze public rest area usage by truck as: distance from the previous rest area; one-way average daily traffic; number and type of available parking spaces; and the presence of picnic tables, vending machines, telephones, and repair facilities.

The Truck Parking Demand Model estimated the nationwide demand for truck parking spaces at public rest areas. It was based on a modification of a mathematical model developed by the Minnesota Department of Transportation (MnDOT) in 1979. The original MnDOT model was based on data collected at Minnesota Interstate rest areas; this modified version applied the same analytical framework on a national level. The new version also incorporated guidelines presented in a 1994 Virginia Department of Transportation study of rest area usage.

The modifications made to the MnDOT model included:

- Adding controls for design hour ratio assumption for average daily traffic figures exceeding 30,000 vehicles.

- Increasing the percentage of mainline traffic entering a rest area that has attributes found by the Capacity Utilization Model to increase utilization of truck parking. These include food facilities, proper lighting, distance from the previous rest area, and diagonal, pullthrough parking.

- Decreasing the vehicles-per-hour space assumption to reflect longer truck parking time, indicating an average parking time per space of 30 minutes instead of 20 minutes.

\section{Findings}

This research documented some important distinctions between public rest areas and privately-owned truck stops. Rest areas on Interstate highways are easily accessible on the right-of-way and provide parking for automobile and truck drivers, as well as rest rooms and vending machines. Most truck stops 
are located close to Interstate ramps and provide services such as fuel, showers, sleeping quarters, and restaurants, in addition to parking space. Differences in the services provided contribute significantly to truck drivers' decisions about where and how long to stop. Table 1 presents the types of services many privately-owned truck stops provide.

\section{Public Rest Area Evaluation}

Researchers first inventoried 1,487 public rest areas with facilities on the Interstate highway system. Then they conducted a direct observation survey along a medium-density Interstate corridor to measure current capacity and demand for short-term (less than 2 hours) and long-term truck parking. Researchers found:

- Of the approximately 576 spaces designated for truck parking at the 7 sites along the observed Interstate corridor, only 20 percent were in public rest areas. The rest were in privately-owned truck stops.

- During the day, half of the rest areas inventoried were full or overflowing; 8 in 10 were full or overflowing at night.

- Few legal spaces were available at rest areas between midnight and 5 a.m. Rest areas reached capacity before truck stops.

- Trucks often park on Interstate shoulders and ramps to avoid parallel parking spaces that some drivers indicated were difficult to use.

- Truck parking capacity at rest areas was reduced by recreational vehicles and cars parked in truck parking areas. Poor designs that caused trucks to park across more than one space also reduced capacity. It was evident that diagonal, pullthrough parking spaces are the most efficient.

- Approximately 42 percent of the 1,487 rest areas have a time limit on truck parking, but only 1 in 10 of these facilities report that the limits are "always" enforced.

Surveys and interviews with truck drivers, motor carrier executives, and truck stop operators generated information about the needs, habits, opinions, and preferences of truck drivers. Most truck drivers and motor carriers believe there is a shortage of adequate long-term or overnight parking facilities for truckers.

Survey results also indicated that truck drivers prefer privately-owned truck stops for long-term or overnight parking. The majority of truck drivers and motor carriers rated truck stops favorably, citing more

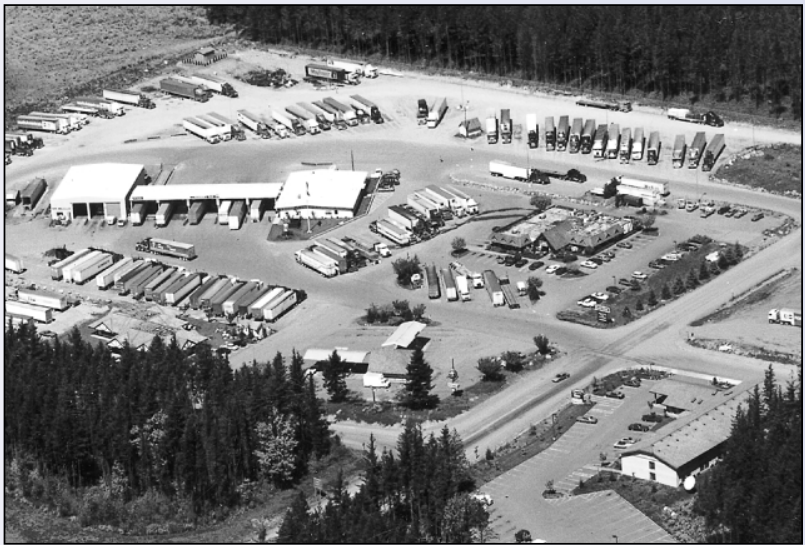

Aerial view of diagonal, pullthrough truck parking facilities.

room to park, availability of food, cleanliness, and feelings of safety and security. However, truck drivers are more likely to use rest areas for short-term stops; those who prefer rest areas report that accessibility is the most important factor in choosing a short-term parking space.

\section{Private Truck Stop Evaluation}

The surveys and direct observation of truck drivers, motor carriers and truck stop operators indicated that privately-owned facilities might offer a means to satisfy the shortage of parking spaces at public rest areas, especially at night. The weighted sample generated by the private truck stop study was used to project a national picture of truck stop capability to meet demand.

The majority of truck stop operators reported that their parking facilities were full or overflowing at night. Over half were filled to capacity 20 nights per month or more. The weighted sample projected an average of 167,000 trucks to be parked at private truck stops in the target population on any given night. This accounted for only 84 percent of the total projected capacity $(185,000)$ of truck parking provided by truck stops along the Interstate highway system nationwide. Even though many truck stops were reportedly filled to capacity at night, this study indicated an overall surplus in parking spaces at privately-owned facilities.

The assessment also determined that about one-third of truck stop operators plan to expand their parking facilities over the next 3 years. This would increase the total projected parking capacity by 15 percent, from the current 185,000 spaces to more than 213,000 .

\section{Database Limitations}

The objective of the truck stop study was to extend the rest area study research effort by including data on private facilities. One research goal was to merge 
Researcher

This study was performed by the Trucking Research Institute, 2200 Mill Road, Alexandria, VA 22314, Telephone: (703) 8381966. Contract No. DTFH61-92C-00092.

\section{Distribution}

This Tech Brief is being distributed according to a standard distribution. Direct distribution is being made to the Regions and Divisions.

\section{Avallability}

The study final report (PB97124705) is available from the National Technical Information Service, Telephone: (703) 6056000 .

\section{Key Words}

safety, rest area, parking, truck stop, fatigue, commercial vehicle safety, highway safety.

\section{Notice}

This Tech Brief is disseminated under the sponsorship of the

Department of Transportation

in the interest of information

exchange. The Tech Brief provides a synopsis of the study's final publication. The Tech Brief does not establish policies or regulations, nor does it imply FHWA endorsement of the conclusions or recommendations. The U.S. Government assumes no liability for its contents or their use.

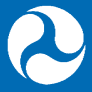

U.S. Department of Transportation Federal Highway Administration

August 1998

Publication No. FHWA-MCRT-98-002 the data collected on truck stops with the existing data on public rest areas to create a unified database that could define both public and private availability and needs. This would be especially relevant for evaluating the impact of excess parking at truck stops on rest area parking needs. Unfortunately, the differences in the two databases, including sample size and geographical factors, prevented the development of a single database.

\section{Substitutability}

If public rest areas and privately-owned truck stops are not direct substitutes for each other, then the existence of a shortfall in rest area parking cannot be absorbed by the presence of excess parking spaces at truck stops. The findings and analyses of the evaluations of the two types of facilities offer certain insights as to whether or not the facilities are interchangeable. These include:

- The direct observation of private truck stops and public rest areas indicated that truck drivers tend to use rest areas for their short-term parking needs, and truck stops for long-term parking needs.

- Significant differences exist in the range of services offered by the two types of parking facilities; truck stops typically offer a wider range of services than rest areas.

- Based on driver survey results, accessibility to parking facilities had some influence on driver choice of a place to stop. Drivers who value accessibility tended to prefer public rest areas.

- Statistical findings indicated that safety features were positive attributes in explaining capacity utilization of truck parking spaces, and a major reason why drivers prefer truck stops.

Based on the information collected and the analytical findings of the study, there was no conclusive evidence that public rest areas and privately-owned truck stops are direct substitutes for each other. Rather, they are complementary, since drivers utilize the two types of facilities for different reasons. As determined by this research, the apparent shortfall of truck parking spaces nationwide continues to a problem for creative solution by both the public and the private sectors.

\section{Recommendations}

The options for expanding truck parking in rest areas nationwide vary substantially in cost, required engineering, administrative responsibilities, and the number of additional parking spaces they may create. The study classified options in four categories: enforcement, modification, renovation, and new construction.

Researchers recommended that the most cost effective way to increase the number of parking spaces to meet current parking requirements is to renovate existing facilities and, where necessary, build new facilities. Researchers also recommended that a public policy approach be developed by state and local officials to analyze current spending practices and integrate truck parking requirements.

\section{Future Research}

Subsequent research in this area is under consideration. In the Transportation Equity Act for the 21st Century, Congress mandated a further study to determine the location and quantity of parking spaces at public rest areas and private rest stops along the National Highway System. The study will include an analysis of projected parking shortages and a plan to reduce or eliminate the shortages. A National Conference on Safety Rest Area Support is also being organized. This conference will bring together interested parties to discuss effective means to increase safe, off-road parking. 